Original Article

\title{
Effect of evidence-based trunk stability exercises on the thickness of the trunk muscles
}

\author{
Hoe-song Yang, PT, PhD ${ }^{1)}$, Yeon-Seop Lee, PT, PhD²), Sun-Ae Jin, PT ${ }^{3)}$ \\ 1) Cheongam College, Republic of Korea \\ 2) Department of Physical Therapy, Daewon University College: 316 Daehak-ro jecheon, Chungbuk, \\ Republic of Korea \\ 3) Department of Public Health Graduate School, Chonnam National University, Republic of Korea
}

\begin{abstract}
Purpose] This study was conducted to investigate the effect of four spine stability exercises on the thickness of the internal and external oblique abdominal muscles, the transverses abdominis, and the multifidus muscles. [Subjects and Methods] Forty healthy adults were enrolled and randomly allocated to four groups. Ten participants performed bridge exercises (BE) while lying on their back; 10 others performed the same exercises with their right legs up (BERL); another 10 performed the same exercises on their side (SBE); and the remaining 10 performed them in a quadruped position with left arm and right leg lifts (QLARL). The participants performed the exercises three times a week for five weeks. The thicknesses of the muscles before and after the interventions were measured using ultrasound. [Results] The results show that the normal bridge exercise significantly thickened the TrA; BERL, the LM; QLARL, the IO; and SBE, the EO and the IO. [Conclusion] All four spine stability exercises were effective. The normal bridge exercise and BERL selectively strengthened the local muscles at the early stage of the treatment. We consider SBE and QLARL should be used in the later stages of treatments because they strengthen both the local and global muscles.

Key words: Trunk muscle thickness, Trunk stabilization, Ultrasonograpy
\end{abstract}

(This article was submitted Jul. 24, 2014, and was accepted Sep. 2, 2014)

\section{INTRODUCTION}

In people with chronic malfunction due to back pain, the trunk muscles are weak, which interferes with the functioning of the spine and increases the risk of further damage to it. Thus, the stabilization of the trunk muscle plays an important role in the prevention and rehabilitation of spine damage ${ }^{1)}$. It is crucial for therapists to find ways to relieve the pain and minimize the malfunction.

Bergmark $^{2}$ reported that local muscles stabilize the spinal segments from their direct or indirect origin to their point of insertion into the spine, and global muscles control the movement of the trunk from their origin to their point of insertion into many spinal segments. In general, local muscles such as the transverse abdominis muscle (TrA) and the multifidus muscle (LM) must be selectively contracted, and the actions of global muscles such as the rectus abdominis or the muscles around the spine need to be minimized to stabilize the body against external resistance in the neutral zone of the spine ${ }^{3}$, because the local muscles, including the internal oblique muscles (IO) and the transverse abdominis

*Corresponding author. Yeon-seop Lee (E-mail: bulchun325@naver.com)

C2015 The Society of Physical Therapy Science. Published by IPEC Inc. This is an open-access article distributed under the terms of the Creative Commons Attribution Non-Commercial No Derivatives (by-ncnd) License $<$ http://creativecommons.org/licenses/by-nc-nd/3.0/> . muscle, increase the tensile force of the thoracolumbar fascia and contribute to the stabilization of the spine ${ }^{4)}$, and the multifidus muscle stabilizes the spinal segments ${ }^{5}$.

Hodges et al. ${ }^{6}$ performed a study using healthy subjects and subjects with chronic or acute back pain to find out how to selectively strengthen the local muscles for trunk stability. The TrA of the healthy subjects activated before its movement, regardless of the movement or direction of the limbs. The TrA of the subjects with chronic back pain activated with a delay before movement, and that of the subjects with acute back pain showed selective weakness of the LM, and the strength and thickness of the muscles were not restored after the back pain disappeared ${ }^{7}$. The stabilization of the spine through the selective muscle strengthening exercise should be improved to prevent pain, malfunction, or a relapse of acute and chronic back pain ${ }^{8)}$.

Many studies of trunk stabilization exercises have been conducted, but most of them have been short studies focusing on the change in muscle strength as measured by electromyograpy (EMG). Non-invasive ultrasound has recently been adapted to measure the thickness and cross-section of local muscles, and has been used in studies of trunk stabilization exercises ${ }^{9,10)}$. This study was conducted to investigate the changes in muscle thicknesses after five weeks of four different trunk stabilization exercises. 
Table 1. The effects of the four kinds of trunk stabilization exercises ( $\mathrm{N}=40)$ (unit: $\mathrm{cm}$ )

\begin{tabular}{lcccccccc}
\hline & \multicolumn{2}{c}{ EO } & \multicolumn{2}{c}{ IO } & \multicolumn{2}{c}{ TrA } & \multicolumn{2}{c}{ LM } \\
\cline { 2 - 9 } & Before & After & Before & After & Before & After & Before & After \\
\hline BE & $0.4 \pm 0.0$ & $0.5 \pm 0.1^{*}$ & $0.6 \pm 0.1$ & $0.7 \pm 0.1$ & $0.3 \pm 0.0$ & $0.4 \pm 0.0^{*}$ & $1.8 \pm 0.1$ & $2.2 \pm 0.2^{*}$ \\
BERL & $0.5 \pm 0.1$ & $0.6 \pm 0.1^{*}$ & $0.7 \pm 0.1$ & $0.8 \pm 0.1^{*}$ & $0.3 \pm 0.0$ & $0.4 \pm 0.0^{*}$ & $2.0 \pm 0.8$ & $2.7 \pm 0.8^{*}$ \\
SEB & $0.5 \pm 0.0$ & $0.7 \pm 0.0^{*}$ & $0.8 \pm 0.2$ & $0.9 \pm 0.2^{*}$ & $0.3 \pm 0.0$ & $0.5 \pm 0.0^{*}$ & $2.0 \pm 0.2$ & $2.5 \pm 0.2^{*}$ \\
QLARL & $0.5 \pm 0.0$ & $0.6 \pm 0.0^{*}$ & $0.7 \pm 0.0$ & $0.9 \pm 0.1^{*}$ & $0.3 \pm 0.1$ & $0.4 \pm 0.1^{*}$ & $2.0 \pm 0.1$ & $2.5 \pm 0.1^{*}$ \\
\hline
\end{tabular}

Values are Mean $\pm \mathrm{SD}, * \mathrm{p}<0.05$, EO: External oblique muscle, IO: Internal oblique muscle, TrA: Transverse abdominis muscle, LM: Lumbar multifidus muscle

\section{SUBJECTS AND METHODS}

\section{Subjects}

The study was performed from March to May 2012. Forty healthy university students were enrolled who had, had no back pain within the previous three months, no structural abnormality of the spine, and no neurological disorders. The objective and methodology of this study were fully explained to all of the subjects, and each understood the information before voluntarily agreeing to participate in this study, based on the Declaration of Helsinki.

\section{Methods}

The 40 participants were randomly allocated to four groups of 10 participants each. They were familiarized beforehand with each exercise method. They were also asked to use a lumbar stabilizer for the abdominal drawing-in maneuver. The thickness of the trunk muscle at rest was measured twice using ultrasound before and after the intervention (intraclass correlation coefficient: range (0.85-0.92).

For the stabilization exercise program, four modified bridge exercises were used. All the participants were asked to use the abdominal drawing-in maneuver while they performed their respective exercises. Each exercise session consisted of three sets of holding the posture for 10 seconds with the trunk straight, resting for five seconds, which was repeated 10 times. The trunk stabilization exercises were a bridging exercise (BE) in which the participants lay on their backs with their feet fixed, and lifted their pelvis until their hips had a $0^{\circ}$ angle; $\left.{ }^{11}\right)$ a bridging exercise with a right leg lift (BERL) in which the participants lay on their backs with their feet fixed and lifted the right leg until it was parallel to the left thigh, and then lifted the pelvis until their hips had a $0^{\circ}$ angle, ${ }^{12)}$ a side bridging exercise (SBE) in which the participants lay on their side using an elbow and the feet for support and lifted their pelvis until their spine became straight ${ }^{13)}$, and a quadruped position with left arm and right leg lifts (QLARL) in which the participants assumed a quadruped position with a straight spine and lifted their left arm and right leg at the same time until their trunk formed a straight line ${ }^{14)}$.

The TrA and the IO were measured using a SonoAce X4 ultrasonograph (Medison, Seoul, Korea) with a 5-7 MHz straight head with the subjects lying straight on their backs with their knees at a $50^{\circ}$ angle and their hip at a $90^{\circ}$ angle. The measurement was performed parallel to the fibers of the $\operatorname{Tr} \mathrm{A}$ at the right axillary midline, in the middle of the iliac crest and the costal angle, and at the $25 \mathrm{~mm}$ anterior lateral margin when the participants completed exhalation ${ }^{15)}$. The LM was measured with the participants lying prone with a pillow under the abdomen to minimize the curve of the spine. Using 5-9 MHz curved head ultrasonography, the head was placed longitudinally on the fourth and fifth lumbar vertebrae, with the facet joint appearing at the center of the monitor ${ }^{10)}$.

Statistical analysis was performed using SPSS version 18.0. The effects and interactions of the four different exercises and the thicknesses of the trunk muscles before and after the exercises were investigated using mixed-model ANOVA. Scheffe's test was performed as a post hoc test. The level of statistical significance used was $\alpha=0.05$.

\section{RESULTS}

The general characteristics of the participants were as follows: mean $\pm \mathrm{SD}$ age (BE group 21.2 \pm 1.2 , BERL group 20.8 \pm 1.4 , SBE group 21.5 \pm 1.5 , and QLARL group $21.6 \pm 1.6$ year); mean $\pm \mathrm{SD}$ height (BE group 166.2 \pm 4.5 , BERL group $164.5 \pm 6.8$, BERL group $167.2 \pm 7.1$, and QLARL group $166.5 \pm 6.5 \mathrm{~cm}$ ); mean $\pm \mathrm{SD}$ weight (BE group $60.1 \pm 8.4$, BERL group 63.2 \pm 3.7 , SBE group $62.2 \pm 2.7$, and QLARL group $61.8 \pm 7.8 \mathrm{~kg}$ ). There were no significant differences among the general characteristics of the groups.

EO thickened more significantly in the BERL group than in the BE group. IO thickened more significantly in the QLARL group than in the BE and BERL groups. TrA thickened more significantly in the SBE group than in the $\mathrm{BE}$ and BERL groups. LM thickened more significantly in the BERL group than in the BE and SBE groups (Table 1).

\section{DISCUSSION}

This study was conducted to compare the thicknesses of muscles before and after four different trunk stabilization exercises which were performed three times a week for five weeks, and to investigate which exercise selectively strengthened the trunk muscles. The abdominal drawing-in maneuver is an exercise that selectively activates the $\operatorname{Tr} A$ and the IO. All the participants were asked to perform the abdominal drawing-in maneuver when they performed their respective exercise ${ }^{8,9)}$.

The results of the present study show the greatest increase in the thickness of EO, $129 \%$, was in the SBE group, followed by $120 \%$ in the QLARL group, $119 \%$ in the BERL group, and 
$116 \%$ in the BE group. In a study of 11 trunk stabilization exercise Okubo et al. ${ }^{12)}$ reported that, the greatest activation of the muscles was observed in the group that performed the side bridge exercise, as measured by needle-EMG. They explained that EO is a global muscle that controls the movement of the spine rather than stabilizing it. Lehman et al. ${ }^{16)}$ reported that $\mathrm{EO}$ about $45 \%$ maximal voluntary muscle contraction during the side bridge exercise. Ekstrom et al. ${ }^{17}$ ) reported that activation of EO on the supporting side was about $69 \%$ of MVC during the side bridge exercise and $20 \%$ of MVC on the non-supporting side. We consider the greatest change in muscle thickness of EO occurred in the SBE and QLARL groups because EO is involved in controlling the rotation of the trunk.

IO thickened by $125 \%$ in the QLARL group, by $118 \%$ in the SBE group, by $116 \%$ in the BERL group, and by $113 \%$ in the EB group. TrA thickened by $147 \%$ in the SBE group, by $137 \%$ in the QLARL group, by $132 \%$ in the BERL group, and by $129 \%$ in the EB group. The results for IO and $\operatorname{TrA}$ were similar; however TrA thickened more significantly in the QLARL group than in the SBE group, unlike IO. Imai et al. ${ }^{13)}$ used needle EMG to measure the effects of different stabilization exercises, and reported an activation of $10 \%$ of $\mathrm{MVC}$ in an EB group, 30\% in a QLARL group, and 35\% in a SBE group. Hodges and Richardson ${ }^{18)}$ reported that weight-bearing and the provision of an unstable support surface were required for neuromuscular control of trunk stabilization muscles. The present study also showed higher activation of the TrA in the SBE group than of the QLARL group because the support surface in the QLARL exercise is smaller than that of the SBE exercise.

LM thickened by $131 \%$ in the BERL group, by $124 \%$ in the QLARL group, and by $119 \%$ in the SBE group. Okubo et al. ${ }^{12)}$ reported that muscle activation in a BERL group was about $51 \%$ of MVC. Ekstrom et al. ${ }^{17)}$ also reported higher activation of LM in a BERL group. Richardson et al. ${ }^{18)}$ also reported high activation of LM and attributed it to the bridging exercise requiring extension of the spine against gravity.

TrA and LM thickened most in all the groups after each intervention. In particular, TrA thickened greatly in the SBE group, and LM, in the BERL group. However, EO significantly thickened by $129 \%$ in the SBE group, which shows that cannot selectively strengthen the local muscles. The reason for this was explained by Rodebold et al. ${ }^{19)}$ who reported that the activation of the global muscles increases in the patients with back pain and that back pain was aggravated due to compression of the spine because of the action of the global muscles. EO thickened least significantly, by $116 \%$, and $\operatorname{TrA}$, by $129 \%$, in BE group, which could be attributed to the early stage of rehabilitation, because the early rehabilitation of patients with an unstable lower back requires minimizes contraction of the global muscles and selective contraction of the local muscle. The present study had several limitations that prevent the generalization of the results. First, it had an insufficient number of healthy subjects and that limits the interpretation of the results. Second, as only four trunk stabilization exercises were used from among many possible exercises, it is difficult to generalize the superior efficacy of the side bridging exercise and the bridging exercise with the leg lifted in strengthening the TrA and the LM. Third, the relative ratio of the global muscle actions to the local muscle actions was uncertain because only the thickness of the EO, from among the global muscles in the trunk, changed. In the future, a further study to investigate the ratio of the global muscle actions to the local muscle actions during spine stabilization exercises should be conducted with patients with unstable spines rather than in healthy people. The thickness of the rectus abdominis and the erector spinae muscle should also be investigated.

\section{REFERENCES}

1) Comerford MJ, Mottram SL: Functional stability re-training: principles and strategies for managing mechanical dysfunction. Man Ther, 2001, 6: 3-14. [Medline] [CrossRef]

2) Bergmark A: Stability of the lumbar spine. A study in mechanical engineering. Acta Orthop Scand Suppl, 1989, 230: 1-54. [Medline] [CrossRef]

3) Panjabi MM: Clinical spinal instability and low back pain. J Electromyogr Kinesiol, 2003, 13: 371-379. [Medline] [CrossRef]

4) Cresswell AG, Grundström $H$, Thorstensson A: Observations on intraabdominal pressure and patterns of abdominal intra-muscular activity in man. Acta Physiol Scand, 1992, 144: 409-418. [Medline] [CrossRef]

5) Neumann DA: Kinesiology of the Musculoskeletal System. Mosby, 2002.

6) Hodges PW, Richardson CA: Altered trunk muscle recruitment in people with low back pain with upper limb movement at different speeds. Arch Phys Med Rehabil, 1999, 80: 1005-1012. [Medline] [CrossRef]

7) Rackwitz B, de Bie R, Limm H, et al.: Segmental stabilizing exercises and low back pain. What is the evidence? A systematic review of randomized controlled trials. Clin Rehabil, 2006, 20: 553-567. [Medline] [CrossRef]

8) Yoo YD, Lee YS: The effect of core stabilization exercises using a sling on pain and muscle strength of patients with chronic low back pain. J Phys Ther Sci, 2012, 24: 671-674. [CrossRef]

9) Teyhen DS, Rieger JL, Westrick RB, et al.: Changes in deep abdominal muscle thickness during common trunk-strengthening exercises using ultrasound imaging. J Orthop Sports Phys Ther, 2008, 38: 596-605. [Medline] [CrossRef]

10) Whittaker JL, Warner MB, Stokes M: Comparison of the sonographic features of the abdominal wall muscles and connective tissues in individuals with and without lumbopelvic pain. J Orthop Sports Phys Ther, 2013, 43: 11-19. [Medline] [CrossRef]

11) Feldwieser FM, Sheeran L, Meana-Esteban A, et al.: Electromyographic analysis of trunk-muscle activity during stable, unstable and unilateral bridging exercises in healthy individuals. Eur Spine J, 2012, 21: S171S186. [Medline] [CrossRef]

12) Okubo Y, Kaneoka K, Imai A, et al.: Electromyographic analysis of transversus abdominis and lumbar multifidus using wire electrodes during lumbar stabilization exercises. J Orthop Sports Phys Ther, 2010, 40: 743-750. [Medline] [CrossRef]

13) Imai A, Kaneoka K, Okubo Y, et al.: Trunk muscle activity during lumbar stabilization exercises on both a stable and unstable surface. J Orthop Sports Phys Ther, 2010, 40: 369-375. [Medline] [CrossRef]

14) Yang HS, Kwon OY, Lee YS: Changes in the thickness of trunk stabilizer muscles according to increased lifting loads in stoop. J Phys Ther Sci, 2013, 25: 121-124. [CrossRef]

15) Ferreira PH, Ferreira ML, Hodges PW: Changes in recruitment of the abdominal muscles in people with low back pain: ultrasound measurement of muscle activity. Spine, 2004, 29: 2560-2566. [Medline] [CrossRef]

16) Lehman GJ, Hoda W, Oliver S: Trunk muscle activity during bridging exercises on and off a Swiss ball. Chiropr Osteopat, 2005, 13: 14-21. [Medline] [CrossRef]

17) Ekstrom RA, Donatelli RA, Carp KC: Electromyographic analysis of core trunk, hip, and thigh muscles during 9 rehabilitation exercises. J Orthop Sports Phys Ther, 2007, 37: 754-762. [Medline] [CrossRef]

18) Hodges PW, Richardson CA: Inefficient muscular stabilization of the lumbar spine associated with low back pain. A motor control evaluation of transversus abdominis. Spine, 1996, 21: 2640-2650. [Medline] [CrossRef]

19) Radebold A, Cholewicki J, Panjabi MM, et al.: Muscle response pattern to sudden trunk loading in healthy individuals and in patients with chronic low back pain. Spine, 2000, 25: 947-954. [Medline] [CrossRef] 